\title{
Headache secondary to nontraumatic brain hemorrhage: a single-center, retrospective clinical study
}

Srdjan Ljubisavljevic ${ }^{1,2}$, Aleksandra Ignjatovic ${ }^{1,3}$, Marina Ljubisavljevic ${ }^{4}$

${ }^{1}$ Faculty of Medicine, University of Nis, Nis, Serbia

${ }^{2}$ Clinic for Neurology, Clinical Center Nis, Nis, Serbia

${ }^{3}$ Institute for Public Health, Nis, Serbia

${ }^{4}$ Clinic for Mental Health Protection, Clinical Center Nis, Nis, Serbia

Submitted: 29 July 2019

Accepted: 14 October 2019

Arch Med Sci

DOI: https://doi.org/10.5114/aoms.2019.90356

Copyright $\odot 2019$ Termedia \& Banach

\section{Abstract}

Introduction: The predictive accuracy of clinical and paraclinical findings for headache occurrence in patients having nontraumatic intracerebral hemorrhage (ICH) was tested.

Material and methods: The medical records of 341 consecutive nontraumatic ICH patients (106 females and 235 males), average age $56.2 \pm 7.7$ years, presenting with headache $(25.5 \%)$ and without a headache $(74.5 \%)$, over a period of 5 years, were retrospectively analyzed.

Results: The presence of focal neurological symptoms $(\mathrm{OR}=0.129,95 \% \mathrm{Cl}$ : $0.044-0.372, p=0.000$ ), loss of consciousness (OR $=0.174,95 \% \mathrm{Cl}: 0.060-$ $0.504, p=0.001)$, body temperature $(\mathrm{OR}=0.586,95 \% \mathrm{Cl}: 0.389-0.882$, $p=0.010)$, and the values of C-reactive protein $(\mathrm{OR}=0.989,95 \% \mathrm{Cl}: 0.978-$ $0.999, p=0.048)$ at admission, as well as the presence of hematoma in the basal ganglia $(\mathrm{OR}=0.308,95 \% \mathrm{Cl}: 0.159-0.596, p=0.000)$ and the presence of arterial hypertension in the medical history $(\mathrm{OR}=0.478,95 \% \mathrm{Cl}: 0.230-0.991$, $p=0.047$ ), are recognized as negative predictors for headache occurrence in $\mathrm{ICH}$. The regular use of antihypertensive therapy is a prominent positive predictor for headache occurrence in ICH $(\mathrm{OR}=1.906,95 \% \mathrm{Cl}: 1.075-3.381$, $p=0.027$ ). Patients presenting with headache had a favorable clinical outcome compared to those without headache in $\mathrm{ICH}$ presentation $(p<0.001)$.

Conclusions: The present results might be clinically useful for considering further diagnostic and therapeutic procedures as early as possible in patients with symptoms clinically suggestive of $\mathrm{ICH}$, with and without headache in ICH clinical presentation. These data require confirmation in a prospective large-scale study.

Key words: headache, nontraumatic intracerebral hemorrhage.

\section{Introduction}

Intracerebral hemorrhage $(\mathrm{ICH})$ is the most severe and least treatable form of stroke, comprising $10 \%$ to $20 \%$ of all strokes worldwide. It is recognized as an emergency medical condition and the most lethal form of stroke, with mortality rates of $30-40 \%$ during the initial hospitalization. Less than half of patients with ICH survive 1 year and less than a third survive 5 years. Many survivors have a significant rate of $\mathrm{ICH}$ recurrence and significant worsening of functional ability $[1,2]$.

The risk factors and pathophysiology of ICH have been considerably studied and are relatively well known. Current knowledge suggests that

\author{
Corresponding author: \\ Assist. Prof. Srdjan \\ Ljubisavljevic, MD, PhD \\ Blvd. Zorana Djindjica 81 \\ 18000 Nis, Serbia \\ Phone: +381 606727222 \\ E-mail: srljub@gmail.com
}


primary prevention remains the most valuable means of reducing the chances of $\mathrm{ICH}$ occurrence and preventing the burden of its personal and social consequences [1]. When ICH does occur, rapid diagnosis and attentive treatment are vital, because early clinical deterioration is common in the first few hours after $\mathrm{ICH}$ onset, and this directly decreases the chances of a good outcome [3, 4]. This clearly suggests that quick ICH diagnosis and medical care have a potent and direct impact on ICH morbidity and mortality.

Intracerebral hemorrhage can present as a heterogeneous disorder, with manifestations that range from no symptoms or mild symptoms to rapid worsening and death. Headaches are commonly reported in hemorrhagic stroke (more often than in ischemic stroke) but the frequency of headaches and other clinical and paraclinical features vary from study to study $[5,6]$. Although the International Classification of Headache Disorders ( $3^{\text {rd }}$ edition; ICHD-3) defines an acute headache attributed to nontraumatic ICH in Section 6.7.2 [7], the knowledge about headache predictors, incidence, and presenting and prominent features in the context of the whole clinical setting of $\mathrm{ICH}$ is far from sufficient. The recognition of predictive factors for headache occurrence in $\mathrm{ICH}$ might be a useful diagnostic tool for considering further diagnostic procedures as early as possible in patients with symptoms suggestive of $\mathrm{ICH}$, both those presenting with headache and those in whom a headache is not expected. That recognition could lead to the diagnosis of $\mathrm{ICH}$ at the earliest, preclinical stage, when adequate pathogenetic therapy could lead to a better clinical course and ICH outcome.

In this study, we evaluated baseline clinical and paraclinical findings of patients with nontraumatic ICH in order to determine which factors are predictive for headache occurrence in $\mathrm{ICH}$ onset, and evaluated the clinical phenotype of this headache.

\section{Material and methods}

\section{Study design and data collection}

The study was performed as a retrospective clinical study approved by the institutional review board of the Faculty of Medicine at the University of Nis (number 01-5518-12 from 10.07.2012). All procedures performed in studies involving human participants were in accordance with the ethical standards of the institutional and/or national research committee and with the 1964 Helsinki Declaration and its later amendments or comparable ethical standards. Informed consent was not required for this study.

A retrospective review of the medical records of consecutive patients at the Clinic for Neurology Clinical Centre of Nis who had experienced a non- traumatic ICH was undertaken. Patients were identified and data were abstracted from our database for the period from January 2013 to June 2017. Clinical data obtained at the time of admission to the hospital were collected. Demographics, medical history, clinical, radiological, and biochemical variables, and other relevant findings were analyzed in reference to headache presence. Patients with nontraumatic ICH with insufficient or inconclusive data $(n=21)$ were excluded from the study.

\section{Study patients}

The data of 341 patients hospitalized at the Clinic for Neurology Clinical Centre of Nis with a firstever nontraumatic ICH between January 2013 and June 2017 were used in this study. Patients were recruited from consecutive patients with acute $\mathrm{ICH}$ confirmed by multi-slice computed tomography (MSCT). The inclusion criteria were: age from 18 years to 65 years, no head trauma, admitted to hospital within $24 \mathrm{~h}$ after symptom onset, and with nontraumatic $\mathrm{ICH}$ as the main final diagnosis at hospital discharge. The time of symptom onset was defined as the witnessed moment of symptom onset or the last known well time. Patients with $\mathrm{ICH}$ resulting from trauma, conversion of an ischemic infarct, carotid or vertebrobasilar dissection, intracranial venous thrombosis, history of acute or chronic infection, malignant diseases, or immunosuppressive treatment were excluded.

\section{Clinical evaluation}

Upon admission to the clinic, all patients underwent routine clinical and neurological examinations as well as biochemical and radiological evaluations. All analyses were performed in close temporal relation to the time of symptom onset.

The presumed etiology of each $\mathrm{ICH}$ was determined based on a combination of clinical and radiological data: $\mathrm{ICH}$ assigned to arterial hypertension and other non-hypertensive causes (arteriovenous malformation, receiving oral anticoagulant therapy [OAT]).

The main clinical presentation of $\mathrm{ICH}$ is estimated based on the presence of signs such as focal neurological symptoms (cranial nerve impairments, pyramid lesions, etc), loss of consciousness, and headache, etc. The neurological presentation was assessed using the Glasgow Coma Scale (GCS) and National Institutes of Health Stroke Scale (NIHSS). Modified Rankin Scale (mRS) scores at discharge, as well as the duration of hospitalization, were also analyzed.

Headache was considered as the secondary to $\mathrm{ICH}$ if the headache appeared in close temporal relation to the other $\mathrm{ICH}$ clinical symptoms and 
signs or if headache led to the diagnosis of $\mathrm{ICH}$ [7]. In all ICH patients presenting with headache, data such as prior headache history, time from onset to peak of pain intensity, accompanying symptoms, pain location and quality, state at time of headache onset, headache duration, and accompanying clinical presentation of ICH were assessed. The presence and features of a headache in patients with disorders of conscience were based on an analysis of the symptoms that preceded the loss of consciousness. The data were obtained from the patients' relatives or their followers at the time of their admission for hospital treatment. These data are assessed as part of the questionnaire conducted in all headache patients treated in our clinic, regardless of headache etiology.

Cardiovascular factors were evaluated upon admission to the clinic, through the assessments of pulse pressure, mean arterial pressure, heart rate, body temperature, the presence of arterial hypertension, and the regularity of antihypertensive therapy use. The presence of diabetes mellitus, chronic renal failure, atrial fibrillation, alcohol abuse, and other comorbidities in medical history were also analyzed. Laboratory tests for glycemia, complete blood cell count, C-reactive protein (CRP), and sedimentation were administered immediately after admission. In patients receiving OAT, hemocoagulation analyses were also performed.

All study patients were categorized according to gender, age, comorbidities, MSCT characteristics, frequency distribution on the clinical scales, and other relevant data.

\section{Radiological evaluation}

Brain MSCT (Aquilion 64 Toshiba) scans were performed upon admission to the hospital. The radiologists who analyzed the images were blinded to other patient data. Intracerebral hematoma was defined as lobar ( $\mathrm{ICH} \mathrm{L}$ ) predominantly located in the cortical/subcortical white matter, in the basal ganglia (ICH BG), in the brainstem (ICH brainstem), or with the presence of intraventricular hemorrhage (IVH). If more locations or expansions of the hematoma were identified, those radiological diagnoses were all noted as combination. The presence of hematoma mass effect was also a determining factor. The results of cerebral angiography were described in relation to the presence or absence of arteriovenous malformation or aneurysms. Patients with $\mathrm{SAH}$ were not included in this study.

\section{Statistical analysis}

Categorical data were analyzed using the $\chi^{2}$ test. All continuous data were analyzed using the MannWhitney test. Univariate and multiple logistic regression was used to assess the association of clin- ical and biochemical markers with the study outcome. Receiver operating characteristic (ROC) curve analysis was used to test the discriminative ability of combined risk factors. The predictive power of different risk factor combinations was compared using the DeLong test. A p-value <0.05 was considered significant. Statistical analyses mostly were performed using SPSS 16.0. ROC curves were compared using MedCalc version 18.

\section{Results}

Within the observed period 341 patients had the final main diagnosis of nontraumatic ICH and completely fulfilled inclusion criteria to form the cohort for data analysis. Their average age was $56.2 \pm 7.7$ years, 235 (68.9\%) were males and 106 (31.1\%) were females.

In 87 (25.5\%) of them, there was a headache in $\mathrm{ICH}$ presentation on admission, while the other 254 (74.5\%) did not have a headache. In most ICH patients with headache it was noted that a headache had developed in close temporal relation to other symptoms of $\mathrm{ICH}$ or had led to the diagnosis of $\mathrm{ICH}$; headache reached the maximum intensity of pain within an hour of the onset (68\%); the pain was referred as stabbing (62\%) or dull (38\%); arising during a rest (48\%) or while performing light physical activity (52\%); headache was described as previously experienced headache (48\%) or as never before experienced headache (52\%); followed by nausea and vomiting (64\%) and without phono/photophobia (75\%); mostly localized in accordance with the site of the hemorrhage (70\%) and without previous history of headaches (51\%) (Figure 1). Detailed demographic, clinical and paraclinical baseline features of $\mathrm{ICH}$ patients in reference to headache occurrence are summarized

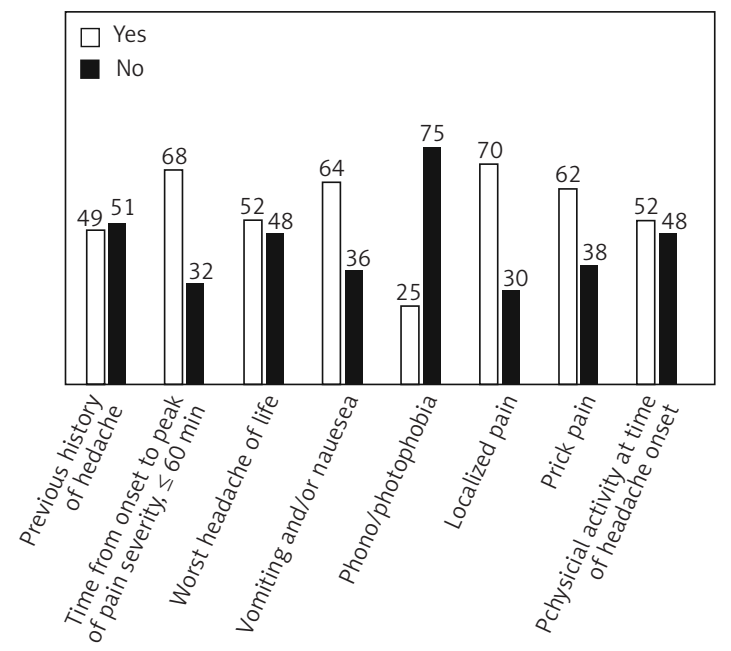

Figure 1. Headache features in intracerebral hemorrhage $(\mathrm{ICH})$ patients. Bars in the graphs represent percentages of $\mathrm{ICH}$ patients presenting with headache in relation to a particular headache feature 
Table I. Demographic, clinical and paraclinical features of intracerebral hemorrhage patients in reference to headache occurrence

\begin{tabular}{|c|c|c|c|c|c|}
\hline \multirow[t]{2}{*}{ Parameter } & \multicolumn{2}{|c|}{ With headache } & \multicolumn{2}{|c|}{ Without headache } & \multirow[t]{2}{*}{$P^{*}$} \\
\hline & Count & $\%$ & Count & $\%$ & \\
\hline \multicolumn{6}{|l|}{ Gender } \\
\hline Male & 52 & 59.8 & 183 & 72.0 & \multirow[t]{2}{*}{0.045} \\
\hline Female & 35 & 40.2 & 71 & 28.0 & \\
\hline Age (years) & $55.47 \pm 9$ & & $56.47 \pm 7$ & & 0.359 \\
\hline \multicolumn{6}{|l|}{ Clinical data } \\
\hline Duration of hospitalization (days) & \multicolumn{2}{|c|}{$8.53 \pm 5.68$} & \multicolumn{2}{|c|}{$7.47 \pm 5.59$} & $0.195 \|$ \\
\hline $\mathrm{GCS}^{\dagger}$ & \multicolumn{2}{|c|}{$10.54 \pm 2.32$} & \multicolumn{2}{|c|}{$10.29 \pm 2.09$} & $0.090 \|$ \\
\hline $\mathrm{NIHSS}^{+}$ & \multicolumn{2}{|c|}{$20.83 \pm 6.30$} & \multicolumn{2}{|c|}{$21.23 \pm 5.92$} & $0.474 \|$ \\
\hline $\mathrm{mRS}^{\dagger}$ & \multicolumn{2}{|c|}{$3.84 \pm 1.61$} & \multicolumn{2}{|c|}{$4.56 \pm 1.52$} & $<0.001$ \\
\hline Mortality & 29 & 18.4 & 58 & 81.6 & $<0.001$ \\
\hline Pulse pressure $[\mathrm{mm} \mathrm{Hg}]^{\dagger}$ & \multicolumn{2}{|c|}{$70.17 \pm 25.94$} & \multicolumn{2}{|c|}{$70.86 \pm 22.88$} & $0.420 \|$ \\
\hline Mean arterial pressure $[\mathrm{mm} \mathrm{Hg}]^{\dagger}$ & \multicolumn{2}{|c|}{$119.94 \pm 23.66$} & \multicolumn{2}{|c|}{$121.59 \pm 24.95$} & $0.451 \|$ \\
\hline Heart beat $[\mathrm{N} / \mathrm{min}]^{\dagger}$ & \multicolumn{2}{|c|}{$78.47 \pm 10.80$} & \multicolumn{2}{|c|}{$81.98 \pm 14.66$} & $0.019 \|$ \\
\hline Body temperature $\left[{ }^{\circ} \mathrm{C}\right]^{\dagger}$ & \multicolumn{2}{|c|}{$37.57 \pm 0.60$} & \multicolumn{2}{|c|}{$37.77 \pm 0.72$} & $0.014 \|$ \\
\hline Arterial hypertension & 67 & 77.0 & 220 & 86.6 & 0.050 \\
\hline Diabetes mellitus & 12 & 13.8 & 34 & 13.4 & 1.000 \\
\hline Chronic renal failure & 4 & 4.6 & 27 & 10.6 & 0.141 \\
\hline Atrial fibrillation & 2 & 2.3 & 6 & 2.4 & 1.000 \\
\hline Alcohol abuse & 5 & 5.7 & 26 & 10.2 & 0.298 \\
\hline Daily use of antihypertensive therapy & 47 & 54.0 & 113 & 44.5 & 0.157 \\
\hline Body mass index $\left[\mathrm{kg} / \mathrm{m}^{2}\right]>30$ & 14 & 16.1 & 47 & 18.5 & 0.730 \\
\hline Neurological symptoms & 52 & 47.1 & 165 & 65.0 & 0.005 \\
\hline Loss of consciousness & 33 & 37.9 & 104 & 40.9 & 0.713 \\
\hline \multicolumn{6}{|l|}{ Radiological diagnosis (hemorrhage localization) } \\
\hline ICH basal ganglia & 15 & 17.2 & 105 & 41.3 & $<0.001$ \\
\hline $\mathrm{ICH}$ lobar & 57 & 65.5 & 37 & 46.9 & 0.004 \\
\hline $\mathrm{ICH}$-brainstem & 13 & 14.9 & 26 & 10.2 & 0.320 \\
\hline IVH & 24 & 27.6 & 98 & 38.6 & 0.086 \\
\hline Mass effect & 34 & 39.1 & 127 & 50.0 & 0.102 \\
\hline Arteriovenous malformation/aneurysm & 9 & 10.3 & 18 & 7.1 & 0.458 \\
\hline \multicolumn{6}{|l|}{ Biochemical data } \\
\hline Glycemia $[\mathrm{mmol} /]^{\dagger}$ & \multicolumn{2}{|c|}{$9.21 \pm 4.13$} & \multicolumn{2}{|c|}{$9.29 \pm 8.14$} & $0.687^{\| \prime}$ \\
\hline WBC $\left[\times 10^{9} /\right]^{\dagger}$ & \multicolumn{2}{|c|}{$12.43 \pm 9.70$} & 12.8 & & $0.649^{l 1}$ \\
\hline $\mathrm{CRP}\left[\mathrm{mg} / \mathrm{l}^{\dagger}\right.$ & 12.15 & & 16.92 & & $0.465^{\|}$ \\
\hline $\mathrm{SE}[\mathrm{N} / \mathrm{h}]^{\dagger}$ & 16.92 & & 15.41 & & $0.871^{\|}$ \\
\hline
\end{tabular}

1 - mean \pm standard deviation, ${ }^{*}$ - chi-squared test, ${ }^{\prime}-$ Mann-Whitney U-test.

GCS - Glasgow Coma Score, NIHSS - National Institutes of Health Stroke Scale, mRS - modified Rankin Score, ICH - intracerebral hemorrhage, WBC - white blood cells, CRP-C-reactive protein, SE-sedimentation rate. 
in Table I. Headache was a rare manifestation of $\mathrm{ICH}$ in women $(p=0.045)$, in patients with a higher heartbeat $(p=0.019)$ and body temperature ( $p=0.014)$ on hospital admission, in ICH patients who had diagnosis of arterial hypertension in the medical history $(p=0.05)$, in those who presented with neurological symptoms on hospital admission ( $p=0.005)$. Patients with headache in the ICH manifestation had better functional recovery on discharge from hospital treatment $(p<0.001)$; the mortality rate was higher in $\mathrm{ICH}$ patients without headache $(p<0.001)$.

Headache was a rare manifestation of $\mathrm{ICH}$ in the cases of hematoma localization in deeper parenchyma structures (with and without mass effects, $p=0.039$ and $p=0.006$, respectively) as well as in lobar localization of hematoma but without mass effect $(p<0.001)$. On the other hand, headache was frequently associated with $\mathrm{ICH}$ in the case of hematoma localization in the brainstem, with the presence of its mass effect $(p=0.039)$. Radiological diagnosis, hemorrhage localization and the presence of its mass effects of $\mathrm{ICH}$ patients in reference to headache occurrence are summarized in Table II.

In the univariate analysis model, the following were identified as positive predictors for headache occurrence in the $\mathrm{ICH}$ clinical presentation: gender $(\mathrm{OR}=1.735,95 \% \mathrm{Cl}: 1.043-2.885, p=0.034)$ and lobar localization of hematoma $(\mathrm{OR}=2.115,95 \% \mathrm{Cl}$ : $1.299-3.576, p=0.003)$, especially in the absence of its mass effects (OR $=2.964,95 \% \mathrm{Cl}: 1.740-$ $5.051, p<0.001)$, as well as the localization of hematoma in the brainstem with a hematoma mass effect $(\mathrm{OR}=3.617,95 \% \mathrm{Cl}: 2.181-11.075, p=0.024)$. On the other hand, the following were recognized as negative predictors for the onset of headache in ICH presentation: heart rate $(\mathrm{OR}=0.980,95 \%$ $\mathrm{Cl}: 0.964-0.999, p=0.043)$ and body temperature $(\mathrm{OR}=0.656,95 \% \mathrm{Cl}: 0.454-0.947, p=0.024)$ at admission, the presence of previous arterial hypertension $(\mathrm{OR}=0.518,95 \% \mathrm{Cl}: 0.280-$ $0.959, p=0.036)$, the presence of neurological symptoms $(\mathrm{OR}=0.481,95 \% \mathrm{Cl}: 0.293-0.788$, $p=0.004)$ and localization of hematoma in the region of the basal ganglia $(O R=0.296,95 \% \mathrm{Cl}$ : $0.161-0.544, p<0.001$ ), in the case of the mass effect being present $(\mathrm{OR}=0.262,95 \% \mathrm{Cl}: 0.101-$ $0.681, p=0.006)$ and in the case where the mass effect is absent $(O R=0.449,95 \% \mathrm{Cl}: 0.218-$ $0.924, p=0.030)$. Detailed data are presented in Table III.

Using multiple logistic regression analysis (backward: Wald method), the following were recognized

Table II. Radiological diagnosis (hemorrhage localization and presence of its mass effects) of intracerebral hemorrhage patients in reference to headache occurrence

\begin{tabular}{|c|c|c|c|c|c|}
\hline \multirow{2}{*}{$\begin{array}{l}\text { Radiological diagnosis } \\
\text { (hemorrhage localization } \\
\text { and mass effect) }\end{array}$} & \multicolumn{2}{|c|}{ With headache } & \multicolumn{2}{|c|}{ Without headache } & \multirow[t]{2}{*}{$P$} \\
\hline & Count & $\%$ & Count & $\%$ & \\
\hline \multicolumn{6}{|l|}{ ICH - basal ganglia } \\
\hline Without mass effect & 10 & 11.5 & 57 & 22.4 & 0.039 \\
\hline With mass effect & 5 & 5.7 & 48 & 18.9 & 0.006 \\
\hline \multicolumn{6}{|l|}{ ICH - lobar } \\
\hline Without mass effect & 47 & 40.2 & 35 & 18.5 & $<0.001$ \\
\hline With mass effect & 72 & 25.3 & 22 & 28.3 & 0.680 \\
\hline \multicolumn{6}{|l|}{$\mathrm{ICH}$ - brainstem } \\
\hline Without mass effect & 6 & 6.9 & 20 & 7.9 & 0.950 \\
\hline With mass effect & 7 & 8.0 & 6 & 2.4 & 0.039 \\
\hline \multicolumn{6}{|l|}{ IVH } \\
\hline Without mass effect & 16 & 18.4 & 51 & 20.1 & 0,853 \\
\hline With mass effect & 8 & 9.2 & 47 & 18.5 & 0.062 \\
\hline \multicolumn{6}{|l|}{ Combination } \\
\hline Without mass effect & 18 & 20.7 & 55 & 21.7 & 0.970 \\
\hline With mass effect & 8 & 9.2 & 45 & 17.7 & 0.085 \\
\hline
\end{tabular}

215 ICH patients had only 1 radiological diagnosis (localization of hemorrhage), 126 ICH patients had 2 or more localizations (combination). ICH - intracerebral hemorrhage, IVH - intraventricular hemorrhage. 
as negative predictors for headache occurrence in $\mathrm{ICH}$ : presence of neurological symptoms (OR $=0.129,95 \% \mathrm{Cl}: 0.044-0.372, p=0.000)$, loss of consciousness (OR $=0.174,95 \% \mathrm{Cl}: 0.060-0.504$, $p=0.001)$, body temperature ( $\mathrm{OR}=0.586,95 \%$ $\mathrm{Cl}: 0.389-0.882, p=0.010)$ and the values of CRP $(\mathrm{OR}=0.989,95 \% \mathrm{Cl}: 0.978-0.999, p=0.048)$ at admission, as well as the presence of hematoma in the basal ganglia $(\mathrm{OR}=0.308,95 \% \mathrm{Cl}$ : $0.159-0.596, p=0.000)$. The presence of arterial hypertension in the previous medical history was recognized as a negative predictor $(\mathrm{OR}=0.478$, $95 \% \mathrm{Cl}: 0.230-0.991, p=0.047)$ while the ordinary use of antihypertensive therapy in these patients is a prominent positive predictor for headache occurrence in $\mathrm{ICH}(\mathrm{OR}=1.906,95 \% \mathrm{Cl}: 1.075-3.381$, $p=0.027$ ) (Table IV).

Discriminative ability of combined clinical and paraclinical predictors for headache occurrence in $\mathrm{ICH}$ clinical presentation is summarized in Table $\mathrm{V}$ and presented through a ROC curve (Figure 1). Different combinations of clinical and biochemical risk factors in Table 5 have shown moderate discriminative ability ( $A \cup C>0.6)$. The combined effect of body temperature + neurological symptoms + arterial hypertension + ICH basal ganglia + loss of consciousness + CRP + ordinary use of antihypertensive therapy statistically improved

Table III. Influence of demographic, clinical and paraclinical features of intracerebral hemorrhage (ICH) patients on headache occurrence in ICH clinical presentation (univariate logistic regression analysis)

\begin{tabular}{|c|c|c|c|}
\hline Parameter & OR & $95 \% \mathrm{Cl}$ & $P$ \\
\hline Gender & 1.735 & $1.043-2.885$ & 0.034 \\
\hline Age & 0.984 & $0.954-1.014$ & 0.299 \\
\hline \multicolumn{4}{|l|}{ Clinical data } \\
\hline GCS & 1.057 & $0.940-1.189$ & 0.351 \\
\hline NIHSS & 0.989 & $0.949-1.030$ & 0.588 \\
\hline Pulse pressure & 0.999 & $0.988-1.009$ & 0.815 \\
\hline $\begin{array}{l}\text { Mean arterial } \\
\text { pressure }\end{array}$ & 0.997 & $0.987-1.007$ & 0.588 \\
\hline Heart beat & 0.980 & $0.961-0.999$ & 0.043 \\
\hline Body temperature & 0.656 & $0.454-0.947$ & 0.024 \\
\hline $\begin{array}{l}\text { Arterial } \\
\text { hypertension }\end{array}$ & 0.518 & $0.280-0.959$ & 0.036 \\
\hline Diabetes mellitus & 1.035 & $0.510-2.102$ & 0.924 \\
\hline $\begin{array}{l}\text { Chronic renal } \\
\text { failure }\end{array}$ & 0.405 & $0.138-1.193$ & 0.101 \\
\hline Alcohol abuse & 0.535 & 0.199-1.439 & 0.215 \\
\hline Atrial fibrillation & 0.973 & $0.193-4.910$ & 0.973 \\
\hline $\begin{array}{l}\text { Daily use of } \\
\text { antihypertensive } \\
\text { therapy }\end{array}$ & 1.466 & $0.899-2.391$ & 0.125 \\
\hline $\begin{array}{l}\text { Body mass } \\
\text { index }>30\end{array}$ & 0.845 & $0.439-1.624$ & 0.613 \\
\hline $\begin{array}{l}\text { Neurological } \\
\text { symptoms }\end{array}$ & 0.481 & $0.293-0.788$ & 0.004 \\
\hline $\begin{array}{l}\text { Loss of con- } \\
\text { sciousness }\end{array}$ & 0.881 & $0.535-1.453$ & 0.621 \\
\hline \multicolumn{4}{|l|}{ Radiological diagnosis } \\
\hline $\begin{array}{l}\text { ICH basal } \\
\text { ganglia: total }\end{array}$ & 0.296 & $0.161-0.544$ & $<0.001$ \\
\hline $\begin{array}{l}\text { Without } \\
\text { mass effect }\end{array}$ & 0.449 & $0.218-0.924$ & 0.030 \\
\hline $\begin{array}{l}\text { With mass } \\
\text { effect }\end{array}$ & 0.262 & $0.101-0.681$ & 0.006 \\
\hline
\end{tabular}

\begin{tabular}{|c|c|c|c|}
\hline ICH lobar: total & 2.155 & $1.299-3.576$ & 0.003 \\
\hline $\begin{array}{l}\text { Without } \\
\text { mass effect }\end{array}$ & 2.964 & $1.740-5.051$ & $<0.001$ \\
\hline $\begin{array}{l}\text { With mass } \\
\text { effect }\end{array}$ & 0.856 & $0.491-1.491$ & 0.582 \\
\hline $\begin{array}{l}\text { ICH brainstem: } \\
\text { total }\end{array}$ & 1.541 & $0.753-3.151$ & 0.237 \\
\hline $\begin{array}{l}\text { Without } \\
\text { mass effect }\end{array}$ & 0.867 & $0.336-2.233$ & 0.767 \\
\hline $\begin{array}{l}\text { With mass } \\
\text { effect }\end{array}$ & 3.617 & $\begin{array}{l}0.181- \\
11.075\end{array}$ & 0.024 \\
\hline IVH: total & 0.606 & $0.356-1.034$ & 0.066 \\
\hline $\begin{array}{l}\text { Without } \\
\text { mass effect }\end{array}$ & 0.897 & $0.481-1.673$ & 0.732 \\
\hline $\begin{array}{l}\text { With mass } \\
\text { effect }\end{array}$ & 0.446 & $0.202-0.986$ & 0.046 \\
\hline $\begin{array}{l}\text { Combination: } \\
\text { total }\end{array}$ & 0.944 & $0.519-1.717$ & 0.850 \\
\hline $\begin{array}{l}\text { Without } \\
\text { mass effect }\end{array}$ & 0.470 & $0.212-1.042$ & 0.063 \\
\hline $\begin{array}{l}\text { With mass } \\
\text { effect }\end{array}$ & 0.642 & $0.391-1.053$ & 0.079 \\
\hline $\begin{array}{l}\text { Arteriovenous } \\
\text { malformation/ } \\
\text { aneurysm }\end{array}$ & 1.513 & $0.653-3.505$ & 0.334 \\
\hline \multicolumn{4}{|l|}{ ochemical data } \\
\hline Glycemia & 0.995 & $0.935-1.058$ & 0.863 \\
\hline WBC & 0.994 & $0.964-1.025$ & 0.709 \\
\hline CRP & 0.993 & $0.982-1.004$ & 0.195 \\
\hline SE & 1.006 & $0.991-1.021$ & 0.445 \\
\hline
\end{tabular}

Total - all ICH patients having named radiological diagnosis - 215 of ICH patients had only 1 radiological diagnosis (localization of hemorrhage), 126 of $\mathrm{ICH}$ patients had 2 or more localizations (combination).

GCS - Glasgow Coma Score, NIHSS - National Institutes of Health Stroke Scale, ICH - intracerebral hemorrhage, IVH - intraventricular hemorrhage, WBC - white blood cells, CRP $C$-reactive protein, $S E$ - sedimentation rate. 
prediction compared to the combined effect of neurological symptoms + ICH basal ganglia ( $\triangle$ AUC: 0.097, DeLong test: $p<0.001$ ), compared to the combined effect of body temperature + neurological symptoms + arterial hypertension ( $\triangle$ AUC: 0.098 , DeLong test: $p<0.001$ ), and compared to body temperature + neurological symptoms + arterial hypertension $+\mathrm{ICH}$ basal ganglia ( $\triangle$ AUC: 0.049 , DeLong test: $p=0.006$ ).

\section{Discussion}

In our study, the frequency of headache as the initial symptom of ICH was $25 \%$, which is in the range of findings obtained in other studies [6, $8,9]$. We found that headache was more common in males; we did not find differences in terms of patient age. Patient age is recognized as an independent predictor of poor short-term clinical outcome of $\mathrm{ICH}[10,11]$. Our results suggest that $\mathrm{ICH}$ patients presenting with headaches had sig- nificantly better outcomes at discharge from hospital; we found no significant differences when comparing the ages of these patients and those presenting without a headache in $\mathrm{ICH}$ who had worse clinical outcomes.

The most relevant risk factor for $\mathrm{ICH}$ occurrence in a patient's medical history is the persistent diagnosis of arterial hypertension [12]. Arterial hypertension is recognized as an independent predictor of $\mathrm{ICH}$ recurrence and worse clinical development [13]. Our results indirectly support this notion. The existence of arterial hypertension in the patient's medical history was a more frequent finding in $\mathrm{ICH}$ patients presenting without a headache and their functional outcome was worse compared to those $\mathrm{ICH}$ patients presenting with headache (Table I).

We found that headache was a more frequent clinical symptom when ICH was located in the upper brain region (cortical/subcortical). This

Table IV. Influence of demographic, clinical and paraclinical features of intracerebral hemorrhage (ICH) patients on headache occurrence in ICH clinical presentation (multiple logistic regression analysis - backward: Wald method)

\begin{tabular}{|lccc|}
\hline Risk factors & OR & $95 \% \mathrm{Cl}$ & $P$ \\
\hline Body temperature & 0.586 & $0.389-0.882$ & 0.010 \\
\hline Arterial hypertension & 0.478 & $0.230-0.991$ & 0.047 \\
\hline Ordinary using of antihypertensive therapy & 1.906 & $1.075-3.381$ & 0.027 \\
\hline Neurological symptoms & 0.129 & $0.044-0.372$ & 0.000 \\
\hline Loss of consciousness & 0.174 & $0.060-0.504$ & 0.001 \\
\hline ICH basal ganglia & 0.308 & $0.159-0.596$ & 0.000 \\
\hline C-reactive protein & 0.989 & $0.978-0.999$ & 0.048 \\
\hline
\end{tabular}

${ }^{*}$ Adjusted for gender, age, GCS, NIHSS, PP, MAP, presence of diabetes mellitus, chronic renal failure, atrial fibrillation and/or aethylismus, $B M I>30$, presence of arteriovenous malformation/aneurysm, ICH-LH,ICH-brainstem and IVH.

Table V. Discriminative ability of combined clinical and paraclinical predictors for headache occurrence in intracerebral hemorrhage clinical presentation

\begin{tabular}{|c|c|c|c|c|c|c|}
\hline Combined risk factors & Sensitivity & Specificity & AUC & SE & $95 \% \mathrm{Cl}$ & $P$ \\
\hline Neurological symptoms + ICH basal ganglia & 48.3 & 72.8 & 0.652 & 0.033 & $0.588-0.717$ & $<0.001$ \\
\hline $\begin{array}{l}\text { Body temperature + neurological symptoms } \\
+ \text { arterial hypertension }\end{array}$ & 52.9 & 70.5 & 0.651 & 0.033 & $0.586-0.717$ & $<0.001$ \\
\hline $\begin{array}{l}\text { Body temperature + neurological symptoms } \\
+ \text { arterial hypertension + ICH basal ganglia }\end{array}$ & 65.5 & 64.6 & 0.700 & 0.030 & $0.640-0.759$ & $<0.001$ \\
\hline $\begin{array}{l}\text { Body temperature + neurological symptoms } \\
+ \text { arterial hypertension + ICH basal ganglia } \\
+ \text { loss of consciousness }\end{array}$ & 80.5 & 55.9 & 0.725 & 0.029 & $0.668-0.783$ & $<0.001$ \\
\hline $\begin{array}{l}\text { Body temperature }+ \text { neurological symptoms } \\
+ \text { arterial hypertension }+\mathrm{ICH} \text { basal ganglia } \\
+ \text { loss of consciousness }+\mathrm{CRP}\end{array}$ & 74.7 & 60.6 & 0.734 & 0.029 & $0.676-0.791$ & $<0.001$ \\
\hline $\begin{array}{l}\text { Body temperature + neurological symptoms } \\
+ \text { arterial hypertension }+\mathrm{ICH} \text { basal ganglia } \\
+ \text { loss of consciousness + CRP + daily use } \\
\text { of antihypertensive therapy }\end{array}$ & 75.9 & 63.8 & 0.749 & 0.028 & $0.694-0.804$ & $<0.001$ \\
\hline
\end{tabular}




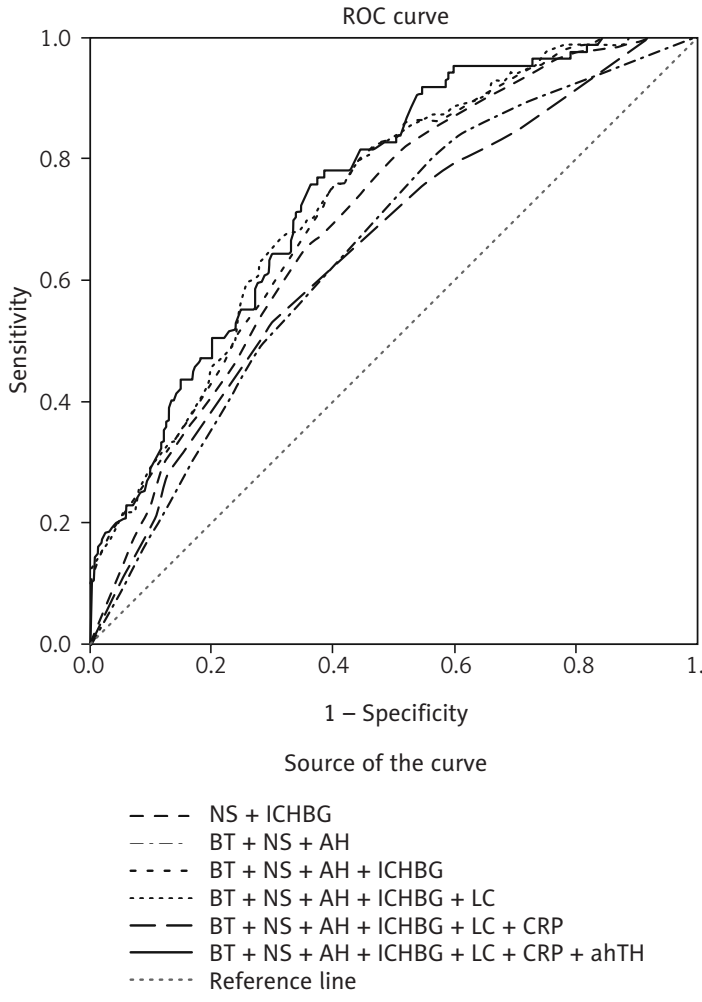

Figure 2. Combined effect of clinical and paraclinical risk factors for headache occurrence in intracerebral hemorrhage clinical presentation (ROC curve analysis)

was proposed in a previous publication [2], but it depended on a lack of hematoma mass effect. Similarly, headache was a prominent symptom when the hematoma was located in the region of the brainstem with a coexisting mass effect of the lesion (Table II). In contrast, when the hemorrhage occurred in deeper brain parenchyma (basal ganglia), we found that headache was rare, independent of the existence of a hematoma mass effect. In contrast to our findings, other studies have suggested a greater frequency of headache in $\mathrm{ICH}$ with deeper brain presentation. Arterial hypertension is crucial in the pathogenesis of deep brain hemorrhage [13]. This is consistent with our finding that headache was a rarer clinical presentation in hypertensive $\mathrm{ICH}$ (ICH patients having arterial hypertension) and, vice versa, headache was a more frequent presentation in so-called nonhypertensive $\mathrm{ICH}$ (ICH patients regularly using antihypertensive therapy).

There is not a large amount of research related to headache secondary to $\mathrm{ICH}$; the data presented here could therefore be significant for at least a partial understanding of the pathophysiology and the clinical phenotype of headache secondary to $\mathrm{ICH}$. The few investigations of the mechanisms underlying $\mathrm{ICH}$ and headache unambiguously indicate that headache is a clinical consequence of direct activation of trigeminovascular nociceptive afferents by the hematoma lesion, so that the pain ensues when a sufficient number of nociceptors are recruited $[6,14]$. Again, the fact that only a quarter of our $\mathrm{ICH}$ patients presented with headaches suggests that hematoma per se is less likely to be the direct cause of the headache. Also, the evidence confirms the absence of a correlation between the size of the cerebrovascular stroke lesion and headache occurrence or severity [15]. The findings presented here could be in line with the notion that mechanisms on the surface of the brain are pivotal in ICH headache pathogenesis $[16,17]$, because headaches were reported as a prominent clinical symptom when the hemorrhage was located in the brainstem and upper brain region (Table II). As the structure at the brain base and its surface are more densely innervated by nociceptive fibers, the more frequent occurrence of headache observed in our study in conditions when the hematoma is distributed over these regions is absolutely to be expected.

The cortical spreading depression may account, among other pathophysiological plausible mechanisms, for headache related to $\mathrm{ICH}$, in particular for the cortical or brainstem located ICH [18]. As shown, the clinical features of headache are nonspecific. That suggests that headache as the sole manifestation or the initial presenting symptom of ICH could easily be misdiagnosed.

Our results show that neurological presentation appears as a negative predictor for headache occurrence; this can be an incomplete pathogenetic connection with our previously described findings of an association between headache occurrence and $\mathrm{ICH}$ location. The most common neurological impairments are caused by lesions that are mostly found in deeper regions of the brain parenchyma; this would be a direct explanation for the rare occurrence of headaches in the settings of pathological neurological findings. In support of this, the loss of consciousness could be recognized as a negative predictor for headache occurrence. The presence of neurological symptoms and loss of consciousness are identified as a negative predictor for headache occurrence in SAH patients [19]. The neurological findings and loss of consciousness are GCS items that change even in the first hours after ICH onset; they are identified as independent prognostic tools for the prediction of ICH clinical evolution $[11,20]$. As ICH patients presenting with headaches have better clinical outcomes (Table I) while both of these parameters (neurological findings and loss of consciousness) are identified as negative predictors for headache occurrence in $\mathrm{ICH}$, the results presented here completely support the findings of other authors. 
The authors of this study emphasize the number of patients involved in the study as a primary advantage of the study, as well as its contributions to this topic, especially for clinicians who are confronted with this issue in everyday clinical practice. On the other hand, as limitations, we emphasize the retrospective nature of the study and the $a b$ sence of data of early hematoma progression and headache occurrence. A future prospective study aimed at examining these links might be particularly clinically useful.

In conclusions, the results presented here of predictors for headache occurrence in $\mathrm{ICH}$ might be useful for clinicians to consider further diagnostic procedures as early as possible in patients with symptoms that are clinically suggestive of ICH who present with headache as well as in those in whom a headache is not expected. Whether a headache is present or absent, it is necessary to consider the possible existence of $\mathrm{ICH}$; further diagnostic tests to confirm ICH, such as CT scan, are standard. Further prospective studies are needed.

\section{Acknowledgements}

This paper is drafted within an internal scientific project of the Faculty of Medicine University of Nis, number 32, and a scientific project of the Ministry of Education, Science and Technological Development of Serbia, number 41018.

\section{Conflict of interest}

The authors declare no conflict of interest.

\section{References}

1. Morgenstern LB, Hemphill JC, Anderson C, et al.; on behalf of the American Heart Association Stroke Council and Council on Cardiovascular Nursing. Guidelines for the management of spontaneous intracerebral hemorrhage: a guideline for healthcare professionals from the American Heart Association/American Stroke Association. Stroke 2010; 41: 2108-29.

2. Poon MT, Fonville AF, Al-Shahi Salman R. Long-term prognosis after intracerebral haemorrhage: systematic review and meta-analysis. J Neurol Neurosurg Psychiatry 2014; 85: 660-7.

3. Moon JS, Janjua N, Ahmed S, et al. Prehospital neurologic deterioration in patients with intracerebral hemorrhage. Crit Care Med 2008; 36: 172-5.

4. Hemphill JC 3rd, Greenberg SM, Anderson CS, et al.; American Heart Association Stroke Council; Council on Cardiovascular and Stroke Nursing; Council on Clinical Cardiology. Guidelines for the management of spontaneous intracerebral hemorrhage a guideline for healthcare professionals from the American Heart Association/ American Stroke Association. Stroke 2015; 46: 2032-60.

5. Goldstein JN, Camargo CA, Pelletier AJ, Edlow JA. Headache in United States emergency departments: demographics, work-up and frequency of pathological diagnoses. Cephalalgia 2006; 26: 684-90.
6. Eden SV, Smith MA, Garcia NM, Hoff JT, Morgenstern LB. Presentation of intracerebral haemorrhage in a community. J Neurol Neurosurg Psychiatry 2006; 77: 340-4.

7. Headache Classification Committee of the International Headache Society (IHS). The International Classification of Headache Disorders, 3rd edition. Cephalalgia 2018; 38: 1-211.

8. van Asch CJ, Luitse MJ, Rinkel GJ, van der Tweel I, Algra A, Klijn CJ. Incidence, case fatality, and functional outcome of intracerebral haemorrhage over time, according to age, sex, and ethnic origin: a systematic review and meta-analysis. Lancet Neurol 2010; 9: 167-76.

9. Fan JS, Huang HH, Chen YC, et al. Emergency department neurologic deterioration in patients with spontaneous intracerebral hemorrhage: incidence, predictors, and prognostic significance. Acad Emerg Med 2012; 19: 133-8.

10. Landtblom AM, Fridriksson S, Boivie J, Hillman J, Johansson G, Johansson I. Sudden onset headache: a prospective study of features, incidence and causes. Cephalalgia 2002; 22: 354-60.

11. Sun W, Pan W, Kranz PG, et al. Predictors of late neurological deterioration after spontaneous intracerebral hemorrhage. Neurocrit Care 2013; 19: 299-305.

12. Biffi A, Anderson CD, Battey TWK, Ayres AM, Greenberg SM, Viswanathan A, Rosand J. Association between blood pressure control and risk of recurrent intracerebral hemorrhage. JAMA 2015; 314: 904-12.

13. Kuramatsu JB, Huttner HB, Schwab S. Advances in the management of intracerebral hemorrhage. J Neural Transm 2013; 120: S35-S41.

14. Feigin VL, Lawes CM, Bennett DA, Barker-Collo SL, Parag V. Worldwide stroke incidence and early case fatality reported in 56 population-based studies: a systematic review. Lancet Neurol 2009; 8: 355-69.

15. Vestergaard K, Andersen G, Nielsen MI, Jensen TS. Headache in stroke. Stroke 1993; 24: 1621-4.

16. Kumral E, Bogousslavsky J, Van Melle G, Regli F, Pierre P. Headache at stroke onset: the Lausanne Stroke Registry. J Neurol Neurosurg Psychiatry 1995; 58: 490-2.

17. Bejot Y, Cordonnier C, Durier J, Aboa-Eboule C, Rouaud O, Giroud M. Intracerebral haemorrhage profiles are changing: results from the Dijon population-based study. Brain 2013; 136: 658-64.

18. Chen SP, Ayata C. Spreading depression in primary and secondary headache disorders. Curr Pain Headache Rep 2016; 20: 44.

19. Ljubisavljevic S, Milosevic V, Stojanov A, Ljubisavljevic M, Dunjic O, Zivkovic M. Identification of clinical and paraclinical findings predictive for headache occurrence during spontaneous subarachnoid hemorrhage. Clin Neurol Neurosurg 2017; 158: 40-5.

20. Cheung RTF, Zou LY. Use of the original, modified, or new intracerebral hemorrhage score to predict mortality and morbidity after intracerebral hemorrhage. Stroke 2003; 34: 1717-22. 